\title{
CARACTERÍSTICAS ENDÓGENAS DAS COMPANHIAS FRENTE AO SEU NÍ- VEL DE DISCLOSURE AMBIENTAL ${ }^{1}$
}

\section{ENDOGENOUS CHARACTERISTICS OF THE COMPANIES IN FRONT OF THEIR ENVIRONMENTAL DISCLOSURE LEVEL}

\author{
Rafael Crisostomo Alves ${ }^{2}$ \\ Centro Universitário Alves Faria \\ rafael.unirv@gmail.com \\ Luiz Roberto Calado \\ Centro Universitário Alves Faria \\ calado@luizcalado.com
}

\section{RESUMO}

Objetivo: $O$ presente artigo teve como objetivo identificar as características endógenas das companhias que explicam o nível de evidenciação das questões ambientais, sob a prática do disclosure ambiental, definido como um conjunto de métodos usados pelas entidades para divulgar suas ações com a natureza.

Fundamento: Visando apresentar o que e como a empresa está se comportando em relação aos recursos naturais, as companhias demandam associar o interesse pela expansão e obtenção de lucros, à interação com o meio ambiente, sendo exigida, por seus stakeholders, maior transparência de suas ações empresariais.

Método: A pesquisa desenvolveu-se por meio da análise dos Relatórios de Sustentabilidade, dos anos de 2010 e 2015, de 52 companhias, consideradas como as maiores em volume de vendas líquidas, pela Revista Exame - Edição Maiores e Melhores 2016. Foram formuladas três hipóteses e testadas a partir da Análise de Regressão com dados em painel, por meio do Modelo de Efeitos Aleatórios. Estas hipóteses englobam desempenho da empresa, potencial de poluição e índice de sustentabilidade empresarial.

Resultados: A Análise de Regressão em Painel demonstrou que a variável Desempenho da Empresa (H1) se confirmou significativa a um nível de 1\%, ou seja, o volume de vendas das companhias possui forte influência sobre o disclosure ambiental praticado pelas empresas investigadas. Concluise que os resultados da pesquisa corroboram com a Teoria da Divulgação, e ratificam os achados de outros estudos relacionados à temática.

Contribuições: A investigação apontou a possibilidade classificação das empresas brasileiras potencialmente poluidoras, e examinar, além das DFPs. Além disso, como se dá a apresentação dos fatores que determinam a divulgação voluntária ambiental, a partir da análise de regressão em painel.

\footnotetext{
${ }^{1}$ Artigo recebido em: 22/07/2018. Revisado por pares em: 26/09/2018. Reformulado em: 01/04/2019. Recomendado para publicação: 01/04/2019 por Vagner Antônio Marques (Editor Adjunto). Publicado em: 26/05/2019. Organização responsável pelo periódico: UFPB

${ }^{2}$ Endereço: Av. Perimetral Norte, noํ4129. Vila João Vaz - Goiânia-GO.
} 
Palavras-chave: Disclosure. Meio Ambiente. Nível. Teoria da Divulgação. Características.

\section{ABSTRACT}

Objective: This article aimed to identify the endogenous characteristics of companies that explain the level of disclosure of environmental issues, under the practice of environmental disclosure, defined as a set of methods used by entities to disclose their actions with nature, aiming to present what and how the company is behaving in relation to natural resources.

Background: In order to present what and how the company is behaving in relation to natural resources, companies demand to associate their interest in the expansion and profit-making, to interact with the environment, and their stakeholders are required to have greater transparency in their actions.

Method: The survey was carried out by analyzing the 2010 and 2015 Sustainability Reports of 52 companies, considered the largest in terms of net sales volume, by Exame Magazine - Major and Best Edition 2016. They were formulated three hypotheses and tested from Regression Analysis with panel data, through the Random Effects Model. These assumptions include company performance, pollution potential and corporate sustainability index.

Results: The Panel Regression Analysis showed that the Company Performance (H1) variable was confirmed at a level of $1 \%$, that is, the companies' sales volume has a strong influence on the environmental disclosure practiced by the companies investigated. It is concluded that the results of the research corroborate with the Theory of Disclosure, and ratify the findings of other studies related to the subject.

Contributions: The research pointed to the possibility of classification of potentially polluting Brazilian companies, and to examine, in addition to the DFPs. In addition, how do we present the factors that determine the voluntary environmental disclosure, from panel regression analysis.

Keywords: Disclosure. Environment. Level. Theory of Disclosure. Characteristics.

\section{INTRODUÇÃO}

Com o advento da industrialização, em meados do século XVIII, a questão ambiental começou a ser percebida como fator relevante para a qualidade de vida das pessoas. O avanço tecnológico permitiu que as indústrias produzissem maior volume de produtos, em períodos cada vez menores de tempo, consumindo, assim, grandes quantidades de recursos humanos e naturais (COSTA \& MARION, 2007). A utilização desordenada desses recursos, com o descarte sem os cuidados necessários, impactou o planeta a ponto de redefinir as ações e projetos, de empresas e sociedade, passando a ter, como foco principal, a associação do avanço econômico à preservação ambiental (PEDRON, 2014).

Toda essa discussão, para Maciel (2012), está envolta no interesse, dos diferentes usuários, por maior comunicação de caráter ambiental, sendo exigida, cada vez mais, pelos tomadores de decisões. Para Coelho (2010) a demanda por este tipo de informação reflete a consciência ecológica adquirida por seus stakeholders ao longo dos últimos anos, como também pela crescente degradação ambiental causada pelas companhias, cujos impactos reverberam, não apenas na sociedade, mas no seu resultado e na sua posição patrimonial e financeira. Essa transparência exigida força, as companhias, à prática do disclosure ambiental, que na concepção de Rosa et al. (2011) é a apresentação das informações relativas às suas atitudes com o meio ambiente, a fim de demonstrar, aos interessados, a sua administração socioambiental. 
No entanto, Pedron (2014) alerta que o disclosure ambiental no Brasil é voluntário, já que não há obrigatoriedade, imposta por legislação, para a divulgação desse tipo de informação, cabendo, ao gestor, a decisão de evidenciar, ou não, aspectos referentes a relação da empresa com o meio ambiente. Todavia, observa-se que a competitividade da companhia pode ser favorecida com as informações acerca dessa relação, buscando parâmetros que colaborem com a proteção dos recursos naturais e o desenvolvimento sustentável, as quais possuem nos relatórios, informações transparentes do seu desempenho ambiental (SILVA, MELO, \& BARBOSA, 2013).

Rosa, Ensslin e Ensslin (2009) concluem que essas informações ambientais, que as empresas buscam evidenciar, têm o intuito de elevar a reputação do negócio, levando em consideração: as necessidades do público, a natureza como utiliza uma fonte de recurso limitado, a responsabilidade profissional da administração e a interação dos diversos sistemas da empresa com a referida evidenciação. Por outro lado, observa-se que, em diversos estudos relacionados à temática como de Costa e Marion (2007), Rover (2009), Braga, Oliveira e Salotti (2009), Murcia (2009), Coelho (2010), Gonçalves et al. (2013), Tannuri (2013), Huppes (2014), Los (2014), Machado (2014), e outros, essa evidenciação ambiental apresenta tipicidades singulares, não havendo um padrão de apresentação, sendo as questões divulgadas conforme interesse e/ou benefícios advindos à companhia.

Destarte, emerge a seguinte questão de pesquisa: “Quais as características endógenas das companhias influenciam no nível disclosure ambiental divulgado no Brasil?"

Com ótica à problemática apresentada, esta pesquisa teve como objetivo precípuo, a partir de um estudo de dados em painel, apresentar as especificidades das empresas que expendem o nível de disclosure ambiental praticado no Brasil.

A transparência na divulgação de informação é o tema central do estudo, que se utiliza do disclosure como apoio, sendo defendido, por Nichi (2016), como de alta relevância para a discussão corporativa, já que é um dos principais meios de comunicação dos gestores com seus usuários, internos e externos.

\section{FUNDAMENTAÇÃO TEÓRICA}

\subsection{Evidenciação Contábil e Disclosure Ambiental}

A evidenciação está ligada aos objetivos da Contabilidade, como garantia de informações claras aos usuários, relativas às atividades empresariais. Sob essa ótica, a evidenciação contábil está presente no processo de identificação, mensuração, organização e divulgação dos eventos econômico-financeiros na forma de informação útil.

Evidenciar ou demonstrar os eventos ambientais, de acordo com Freitas e Strassburg (2007), está relacionado com as atividades operacionais de cada setor que afetam a continuidade das empresas, a qualidade de vida das pessoas e o ecossistema. Cabe a Contabilidade o papel de segregar os gastos e provisões relativas ao meio ambiente, efetuar sua classificação e quantificação, de acordo com sua ocorrência, importância e finalidade.

Rosa et al. (2010) complementam expondo que o disclosure ambiental é composto por um conjunto de métodos usados pelas entidades para divulgar suas ações com a natureza, visando apresentar o que e como a empresa está se comportando em relação aos recursos naturais. Ainda segundo os autores, qualifica-se por demonstrar elementos financeiros e não financeiros derivados do vínculo entre entidade e meio ambiente. Esses resultados podem ser publicados anualmente, por meio de relatórios sociais e administrativos específicos como, por exemplo, o Relatório de Sustentabilidade (GUBIANI et al., 2010).

Gray e Bebbington (2001) descrevem algumas das possíveis razões para as empresas divulgarem informações de caráter ambiental, sendo elas: legitimar suas atividades; desenvolver a 
imagem corporativa; se antecipar a ações regulatórias; o impacto positivo no preço das ações; vantagens competitivas; e respeito ao direito à informação dos acionistas e stakeholders; entre outras.

Além disso, Rover (2013) cita que muitas vezes os reais motivos para o disclosure são complexos, e estão diretamente relacionados aos custos para produzi-lo e os benefícios gerados à entidade, sendo estes difíceis de serem mensurados com confiabilidade. Quando a empresa passa a valorizar sua relação com o meio ambiente e toma medidas preventivas, sua imagem perante a opinião pública tende a apresentar conotação diferenciada. Segundo Freitas e Strassburg (2007), valorizar sua preocupação com o meio ambiente tem um forte papel, entre outros, na manutenção dos clientes atuais e atração de novos consumidores.

\subsubsection{Pesquisas Sobre Disclosure Ambiental}

Na visão de Damak-Ayadi (2008) as pesquisas empíricas sobre disclosure ambiental classificam-se em três tipos, a saber: estudos descritivos, que relatam a natureza e extensão da divulgação, assim como a comparação entre países, setores e/ou períodos; estudos explicativos, que tratam dos determinantes da divulgação social e ambiental; e estudos sobre o impacto da informação social e ambiental, principalmente quanto à reação do mercado.

Estudos sobre disclosure ambiental têm demonstrado que existem diferenças significativas entre países (GRAY, KOU HY, \& LAVERS, 1995a). Ho e Taylor (2007) declaram que os trabalhos empíricos de evidenciação social e ambiental são predominantemente realizados nos Estados Unidos, Canadá, Austrália, Nova Zelândia e Reino Unido. Corroborando esta pesquisa, Murcia et al. (2008b), que analisaram a literatura de disclosure ambiental internacional de 1997 a 2007, acrescentam que nenhum dos 145 autores analisados estava afiliado a uma universidade brasileira, o que representou uma motivação para a realização de pesquisas de evidenciação ambiental no Brasil constatando que a categoria de contabilidade e evidenciação ambiental representa cerca de $10 \%$ das publicações.

No Brasil, foram identificados dois estudos sobre determinantes do disclosure ambiental, o de Murcia et al. (2008a) e o de Braga e Salotti (2008).

Um diferencial proposto nesta pesquisa é investigar, por meio de uma estrutura conceitual de análise, empresas brasileiras potencialmente poluidoras, ao longo de dez anos, e examinar, além das DFPs, os relatórios socioambientais. Além disso, pretende-se explicar os fatores que determinam a divulgação voluntária ambiental, a partir da análise de regressão em painel.

Destarte, as primeiras pesquisas que abordaram a temática ambiental, relacionando-a com a Ciência Contábil, foram desenvolvidas por Ribeiro, nos anos de 1992 e 1998, em sua dissertação de mestrado e sua tese de doutorado, respectivamente. Com ótica a evidenciação de informações ambientais, merece destaque dois trabalhos que discutiram o disclosure ambiental no setor de papel e celulose, a saber: o estudo de Paiva (2001) que abordou especificamente a evidenciação dos gastos ambientais no Brasil, discutindo as formas de evidenciação existentes e a necessidade de novos modelos que relacionem as atividades da empresa com o meio ambiente; e o trabalho de Nossa (2002) que investigou o disclosure ambiental das maiores empresas, por vendas, brasileiras e estrangeiras, a partir da análise de conteúdo de relatórios anuais e ambientais.

Além dessas pesquisas pioneiras, a revisão bibliográfica possibilitou identificar outros estudos relevantes que abordaram a evidenciação ambiental e suas especificidades, sendo detalhados no Quadro 1. 


\begin{tabular}{|c|c|}
\hline \multicolumn{2}{|r|}{ Quadro 1 - Estudos relacionados à temática } \\
\hline Autor (es) & Objetivo / Resultados \\
\hline $\begin{array}{c}\text { Costa e Marion } \\
\text { (2007) }\end{array}$ & $\begin{array}{l}\text { O artigo teve como objetivo examinar as informações ambientais disponibilizadas nos sites das em- } \\
\text { presas e da Bolsa de Valores de São Paulo (BOVESPA), do segmento de Papel e Celulose, e constatou- } \\
\text { se que a falta de uniformidade na estrutura dos relatórios divulgados pelas entidades prejudica a } \\
\text { análise das informações. }\end{array}$ \\
\hline $\begin{array}{l}\text { Rover et al. } \\
\qquad(2008)\end{array}$ & $\begin{array}{l}\text { O objetivo do estudo fora examinar as informações ambientais divulgadas voluntariamente por em- } \\
\text { presas brasileiras, a partir da análise de conteúdo das DFP's do ano 2006. Como resultado verificou- } \\
\text { se que a maioria das informações ambientais é declarativa, do tipo positiva, localizada no Relatório } \\
\text { da Administração e não auditada. }\end{array}$ \\
\hline $\begin{array}{l}\text { Braga, Oliveira } \\
\text { e Salotti (2009) }\end{array}$ & $\begin{array}{l}\text { O objetivo da pesquisa consistiu em avaliar a influência de determinadas variáveis sobre o nível de } \\
\text { divulgação ambiental nas demonstrações contábeis de empresas brasileiras. As evidências empíricas } \\
\text { apontam que a maior parte das informações foi encontrada no relatório da administração; sendo elas } \\
\text { do tipo declarativa; e de caráter favorável à imagem da empresa. }\end{array}$ \\
\hline $\begin{array}{l}\text { Murcia } \\
(2009)\end{array}$ & $\begin{array}{l}\text { O objetivo do trabalho fora identificar os fatores que explicam o nível de disclosure voluntário de } \\
\text { companhias abertas no Brasil. A análise dos dados constatou que existe associação entre o nível de } \\
\text { disclosure das empresas e o setor de atuação. }\end{array}$ \\
\hline Calixto (2011) & $\begin{array}{l}\text { O trabalho objetivou analisar comparativamente as informações socioambientais divulgadas pelas } \\
\text { companhias latino-americanas nos seus relatórios. Quanto à evolução e forma de divulgação de in- } \\
\text { formações, tem-se o relatório anual como o principal canal utilizado pelas companhias para destacar } \\
\text { tais informações, seguido do relatório de sustentabilidade. }\end{array}$ \\
\hline $\begin{array}{l}\text { Rover et al. } \\
\qquad(2011)\end{array}$ & $\begin{array}{l}\text { O objetivo no estudo foi identificar os fatores que determinam a divulgação voluntária ambiental } \\
\text { pelas empresas brasileiras potencialmente poluidoras. Os resultados mostram que, nos três anos } \\
\text { analisados, as } 57 \text { empresas que compõem a amostra do estudo evidenciaram um total de } 6.182 \text { sen- } \\
\text { tenças ambientais, } 73 \% \text { delas divulgadas nos RS e } 27 \% \text { nas DFP's. }\end{array}$ \\
\hline $\begin{array}{c}\text { Costa et al. } \\
\text { (2013) }\end{array}$ & $\begin{array}{l}\text { O artigo teve como objetivo analisar o conteúdo da divulgação de informações acerca das dimensões } \\
\text { da sustentabilidade empresarial nos relatórios de empresas premiadas por suas práticas de respon- } \\
\text { sabilidade socioambiental. Os resultados apontaram preponderância da dimensão social, especial- } \\
\text { mente de âmbito externo, e do disclosure quantitativo não monetário. }\end{array}$ \\
\hline
\end{tabular}

Fonte: Elaborado pelo autor (2017).

Outras pesquisas contribuíram de igual forma para as discussões e evolução do assunto na academia. É válido levantar, também, o estudo de Rover (2009), que, em sua dissertação de mestrado, analisa as características da informação ambiental e os fatores que determinam sua divulgação voluntária pelas empresas brasileiras potencialmente poluidoras. E conclui-se que os achados da pesquisa corroboraram com a Teoria da Divulgação Voluntária, na medida em que as empresas divulgaram voluntariamente poucas informações negativas a respeito de suas práticas ambientais.

Por fim, tem-se o estudo, mais recente, de Rufino (2014) que teve como objetivo identificar os fatores determinantes da divulgação voluntária de informações de caráter social e ambiental das empresas, no período de 2010 a 2012. Os resultados sugeriram que o tamanho da empresa, a rentabilidade, a reputação e o setor regulado foram fatores considerados determinantes da divulgação voluntária social.

A partir do apresentado observa-se que o assunto ainda é incipiente, demonstrando necessidade de estudos que refutem ou confirmem as preposições levantadas, a fim de contribuir com a ciência na construção de novas teorias no futuro.

\subsubsection{Teorias Sobre Evidenciação Ambiental}

Diversos são os estudos e teorias que tentam explicar os motivos que levam as empresas a evidenciarem seu comportamento ambiental, existindo diferentes abordagens para explicá-los. $\mathrm{O}$ Quadro 2 apresenta, de forma objetiva, algumas teorias e suas linhas de defesa. 


\begin{tabular}{|c|c|}
\hline \multicolumn{2}{|r|}{ Quadro 2 - Teorias e a Evidenciação Ambiental } \\
\hline Teoria & Linhas de defesa \\
\hline $\begin{array}{l}\text { Economia do custo da } \\
\text { transação }\end{array}$ & $\begin{array}{l}\text { As empresas se engajarão nos relatórios de sustentabilidade quando estas possuam um } \\
\text { claro incentivo econômico para fazê-lo. Menores custos de evidenciação ambiental au- } \\
\text { mentam a probabilidade de adoção. }\end{array}$ \\
\hline Teoria da agência & $\begin{array}{l}\text { A evidenciação da sustentabilidade pode ser inadequada para enfrentar as preocupações } \\
\text { conflitantes do principal. }\end{array}$ \\
\hline Teoria institucional & $\begin{array}{l}\text { As empresas podem se tornar mais legítimas, adequando nas indústrias emergentes às } \\
\text { tendências da evidenciação ambiental. }\end{array}$ \\
\hline Ecologia Organizacional & $\begin{array}{l}\text { A evidenciação da sustentabilidade estará na visão das nas novas organizações à medida } \\
\text { que estas se adequarem mais ao triple bottom line. }\end{array}$ \\
\hline $\begin{array}{l}\text { Teoria da dependência de } \\
\text { recursos }\end{array}$ & $\begin{array}{l}\text { A evidenciação da sustentabilidade talvez seja o resultado das influências do poder antes } \\
\text { que das considerações econômicas. Os relatórios de sustentabilidade poderiam implicar } \\
\text { menos regulação de agências do governo. }\end{array}$ \\
\hline $\begin{array}{l}\text { Visão da firma baseada } \\
\text { nos recursos }\end{array}$ & A evidenciação ambiental pode fornecer uma vantagem competitiva. \\
\hline $\begin{array}{l}\text { Teoria dos escalões } \\
\text { superiores }\end{array}$ & A evidenciação da sustentabilidade é uma função da gestão de fundões cognitivos. \\
\hline Teoria das redes sociais & $\begin{array}{l}\text { Os relatórios de sustentabilidade se espalham através das redes de empresas interconec- } \\
\text { tadas. }\end{array}$ \\
\hline Teoria dos sinais & $\begin{array}{l}\text { A evidenciação da sustentabilidade pode ser usada para sinalizar o tipo de sustentabili- } \\
\text { dade da empresa aos stakeholders. }\end{array}$ \\
\hline $\begin{array}{l}\text { Teoria do disclosure } \\
\text { voluntário }\end{array}$ & $\begin{array}{l}\text { As empresas com um maior desempenho ambiental buscarão se distinguir da concorrên- } \\
\text { cia ao divulgarem informação favorável quanto à sua performance ambiental. }\end{array}$ \\
\hline Teoria da legitimidade & $\begin{array}{l}\text { As organizações adotam várias medidas e escolhas estratégicas, principalmente, por meio } \\
\text { da comunicação, para garantir que seu desempenho seja percebido como legítimo. }\end{array}$ \\
\hline Teoria do stakeholder & $\begin{array}{l}\text { O comportamento gerencial adotado pelas empresas é em resposta a grupos e indivíduos } \\
\text { que podem afetar a organização. }\end{array}$ \\
\hline
\end{tabular}

Fonte: Nikolaeva e Bicho (2011).

Além das teorias apresentadas, a evidenciação ambiental pode ser explicada, também, pela Teoria da Divulgação, que de acordo com Sousa (2013) pode ser um fenômeno endógeno ou exógeno. Para a primeira, a autora expõe que, pode ser baseada em associações e/ou incentivos, e a segunda baseada em julgamentos.

Neste mesmo sentido, Verrecchia (2001) categoriza as pesquisas relacionadas a evidenciação em: Pesquisa sobre divulgação baseada em associação; Pesquisa sobre divulgação baseada em discricionariedade; e Pesquisa sobre divulgação baseada em eficiência. O Quadro 3 demonstra as principais características da Teoria da Divulgação.

\begin{tabular}{|l|c|c|}
\multicolumn{2}{|c|}{ Quadro 3 - Categorias da Teoria da Divulgação } \\
\cline { 2 - 3 } \multicolumn{2}{|c|}{ Categoria } & Características da Evidenciação \\
\hline Associação & ex post & Processo de Divulgação \\
\hline Discricionariedade de ocorrência do disclosure & Exógeno \\
\hline Eficiência & ex post & Endógeno \\
\hline
\end{tabular}

Fonte: Adaptado de Verrecchia (2001).

Como se observa no Quadro 3, a Divulgação baseada em Eficiência trata-se de uma análise antes da evidenciação ocorrer, ou seja, permite identificar quais informações são preferíveis pelos stakeholders, sendo que as companhias têm como propósito apresentar apenas aquelas agradáveis aos seus usuários, e que possibilitarão ganhos na eficiência e melhor visão dos investidores.

Nas categorias Associação e Discricionariedade, a divulgação já ocorreu, sendo avaliadas, na primeira, as relações entre a evidenciação e as alterações provocadas no valor das ações ou no vo- 
lume de transações, tem-se uma ótica exógena. E na segunda categoria procura-se entender os motivos em divulgar as informações, com ótica endógena, questionando, dessa forma, por que a empresa faz ou não a divulgação de determinada informação.

A presente pesquisa fundamenta-se na Teoria da Divulgação, especificamente, na segunda categoria apresentada por Verrecchia (2001), a divulgação baseada em discricionariedade. A partir dela, foram investigadas as características do disclosure ambiental realizado pelas companhias objeto de estudo.

\section{METODOLOGIA DA PESQUISA}

O presente estudo classificou-se como teórico-empírico de caráter descritivo-explicativo, pois teve como objetivo primordial, a descrição das características de determinada população ou fenômeno e, também, o estabelecimento de relações entre as variáveis (GIL, 2009). Quanto à abordagem do problema, a pesquisa se caracterizou como quali-quanti.

A população da pesquisa consistiu nas empresas listadas na Revista Exame - Edição Especial Maiores e Melhores 2016, como as 100 maiores companhias do país em vendas líquidas. Esse ranking da Revista Abril é elaborado pela Fundação Instituto de Pesquisas Contábeis, Atuariais e Financeiras (FIPECAFI) ${ }^{2}$, sob coordenação dos professores Nelson de Carvalho e Ariovaldo dos Santos, com o apoio de uma equipe de 17 profissionais, e leva em consideração índices e cálculos robustos para sua construção, com análise técnica rigorosa pela equipe. Essa edição da revista tem por objetivo medir a performance das empresas individualmente, apresentando aquelas que tiveram melhor desempenho em vendas líquidas; maiores por patrimônio; por lucros; por prejuízos; aquelas que mais cresceram; as mais rentáveis, dentre outras classificações.

A seleção final da amostra se deu por meio da acessibilidade dos Relatórios de Sustentabilidade, sendo excluídas da pesquisa, as companhias que, por ventura, não tiveram seus documentos disponíveis, simultaneamente, nos anos de 2010 e 2015. No que se refere ao corte temporal, primeiramente, à escolha do ano de 2015 fora em razão de ser o ano mais recente de divulgação dos Relatórios de Sustentabilidade analisados, visto que para sua publicação não possui data limite, ocorrendo, na maioria das vezes, entre os meses de maio e agosto do ano posterior; já o ano de 2010 fora em decorrência da acessibilidade dos documentos, via páginas online, uma vez que poucas companhias apresentaram histórico de arquivos dos materiais investigados anterior a este ano.

A estrutura conceitual da pesquisa se baseou no estudo feito por Nossa (2002) e Rover (2009), com algumas adaptações. Dessa forma, a análise fora dividida em sete categorias, a saber: Políticas Ambientais; Sistema de Gerenciamento Ambiental; Impacto de Produtos e Processos no Meio Ambiente; Informações Financeiras Ambientais; Educação e Pesquisa Ambiental; Mercado de Créditos de Carbono; e Outras Informações Ambientais.

A pesquisa utilizou, para coleta de dados, fontes secundárias, compostas pelos Relatórios de Sustentabilidade (RS) das empresas investigadas. Os relatórios foram obtidos por meio da busca eletrônica, sendo o acesso realizado através da consulta nos sítios das empresas.

Quanto a análise de correspondência (Anacor) aplicada pretende estudar a relação entre duas variáveis nominais. (Pestana \& Gageiro, 2003). De maneira geral, a utilização da Anacor torna-se interessante como complemento ao Teste do Qui-quadrado e esse último é, também, um pressuposto para a utilização dessa técnica. Nesse sentido, a existência de uma relação significativa entre as variáveis em estudo, mensurada por meio do Qui-quadrado, é normalmente realizada antes da utilização da Anacor. Uma das principais vantagens dessa técnica é a visualização das relações através

${ }^{2}$ A parceria Revista Exame/FIPECAFI vem desde 1996 e une o alto rigor técnico da pesquisa à liderança da Revista Exame como revista de negócios de excelência (FIPECAFI, 2017). 
do mapa perceptual que auxilia na interpretação das associações entre as variáveis, permitindo ao pesquisador realizar inferências, ainda que de modo exploratório.

De maneira prática, a Anacor utiliza o teste Qui-quadrado para padronizar os valores das frequências e formar a base para as associações, sendo que a partir de uma tabela de contingência calcula-se as diferenças entre as frequências esperadas e observadas (Lima, 2007). Em seguida, a técnica permite criar uma medida de distância que é visualizada, geralmente, em um espaço bidimensional.

Para o cálculo da métrica da pesquisa, fora utilizada a técnica de Análise de Conteúdo, que tem como finalidade o estudo das características das informações de forma rígida, utilizando números para reunir as evidenciações ambientais como unidade de documento (GIL, 2009). O índice fora calculado a partir do número de proposições evidenciadas pela companhia, dividido pelo número total de evidenciações existentes. Por fim, o tratamento dos dados se deu em Microsoft Office Excel 2010 e software estatístico IBM® SPSS® Statistics 21 Premium e EViews ${ }^{\circledR} 9.5$ Student Version Lite, com posterior construção de tabelas e gráficos para melhor visualização dos resultados encontrados.

Vale ressaltar que as variáveis, relacionadas às características endógenas das empresas investigadas, que foram consideradas pelo estudo, estão descritas, individualmente, nas hipóteses elaboradas.

\subsection{Hipóteses de Pesquisa}

No que se refere as características individuais da empresa, consideradas variáveis amplamente utilizadas em trabalhos de natureza semelhante, como de Nossa (2002); Cunha e Ribeiro (2008); Rover (2009); Murcia (2009) e Braga, Oliveira e Salotti (2009), foram formuladas três hipóteses, envolvendo: Desempenho da Empresa; Potencial de Poluição e Índice de Sustentabilidade Empresarial (ISE).

\subsubsection{Desempenho da Empresa}

De acordo com o estudo de Verrecchia (2001), existe uma relação positiva entre as divulgações voluntárias e a receita da empresa, sendo as vendas líquidas da companhia uma determinante relevante do seu desempenho.

Para Salotti e Yamamoto (2008) espera-se que empresas com melhor desempenho apresente maior nível de disclosure voluntário. Para os autores essa relação pode ser explicada através do conceito de seleção adversa: "se o desempenho da empresa é muito bom é natural que a divulgação seja incentivada [...]. Por outro lado, se o desempenho é ruim, não há a necessidade de a empresa incorrer em custos de divulgação, pois o efeito para o mercado é o mesmo".

Desta feita, a proxy considerada para análise do desempenho da companhia fora o volume de vendas líquidas. "H1: O nível de disclosure ambiental tem correlação positiva com o desempenho da empresa".

\subsubsection{Potencial de Poluição}

Com o advento da Lei n. 6.938, de 31 de agosto de 1981, fora estabelecida a Política Nacional do Meio Ambiente (PNMA), cujo objetivo, de acordo com o artigo segundo "é a preservação, melhoria e recuperação da qualidade ambiental propícia à vida, visando assegurar, no País, condições ao desenvolvimento socioeconômico, aos interesses da segurança nacional e à proteção da dignidade da vida humana" (BRASIL, 1981). 
Dentre os propósitos dessa política tem-se a compatibilização do desenvolvimento econômico-social com a preservação da qualidade do meio ambiente e do equilíbrio ecológico, além do estabelecimento de critérios e padrões de qualidade ambiental, e a preservação e restauração dos recursos naturais com vistas à sua utilização de forma racional e disponibilidade permanente.

A principal contribuição da Política Nacional do Meio Ambiente ao estudo, através da Lei n. 10.165, de 27 de dezembro de 2000, fora a classificação das atividades potencialmente poluidoras e/ou utilizadoras dos recursos ambientais. Essa classificação é calculada com base no grau de poluição e utilização de recursos naturais, podendo ser: AAlto; Alto; MMédio; Médio e Baixo.

Observa-se que empresas identificadas com atividades de alto impacto ambiental, podendo ser AAlto ou Alto, possuem grande utilização de recursos naturais, e por consequência necessitam demonstrar, aos stakeholders, a preocupação eminente de sua atividade e a responsabilidade ambiental. Portanto, infere-se que quanto maior a classificação na Política Nacional do Meio Ambiente, maior deve ser o nível de evidenciação ambiental. “H2: Empresas classificadas, na Política Nacional do Meio Ambiente, com atividades de alto impacto ambiental (AAlto e Alto) possuem maior nível de disclosure ambiental".

\subsection{3 Índice de Sustentabilidade Empresarial (ISE)}

A concepção de desenvolvimento sustentável tem sido valorizada mundialmente nos mercados financeiros, visto que os investidores têm buscado por investimentos socialmente responsáveis, determinando a constituição de índices de ações, para constatar as empresas que adotam esses princípios em vários países (SILVA \& QUELHAS, 2006).

O Investimento Sustentável e Responsável (ISR) ${ }^{3}$ refere-se à sistemática de aplicação de capital que associa os propósitos econômicos do investidor com seus interesses e responsabilidade a respeito de questões de governança, da sociedade e do meio ambiente, sendo o mercado de ações um importante instrumento para incentivar os investidores a aderirem esses conceitos, por intermédio da criação dos índices de sustentabilidade que, segundo pesquisas, já são mais de 50 existentes em várias bolsas no mundo (MACEDO et al.,2012).

Para atender essa necessidade, no Brasil, a BM\&FBOVESPA, com o apoio de outras instituições, criou o Índice de Sustentabilidade Empresarial (ISE), sendo o quarto índice de ações desenvolvido no mundo com o intuito de demonstrar o resultado do mercado, formado por empresas que exercem políticas de gestão sustentável (MARCONDES \& BACARJI, 2010).

O ISE é um instrumento que possibilita comparar a avaliação do desempenho das empresas inseridas na BM\&FBOVESPA, no âmbito de uma economia eficiente, controle do meio ambiente, igualdade social e governança corporativa, a fim de desenvolver um mercado de investimento proporcional com as necessidades da atual comunidade e incentivar o compromisso moral das organizações, a transparência na divulgação de suas transações e responsabilidade com o desenvolvimento sustentável (MACEDO et al., 2012).

Nesta ótica, empresas pertencentes ao índice devem possuir maior responsabilidade com as questões ambientais, e, além disso, priorizar a transparência de suas ações, possuindo, dessa forma, melhor nível de disclosure ambiental.

A análise da amostra estudada, em relação à composição da carteira do ISE, fora realizada por meio de uma variável dicotômica, com valor $=0$ (zero), caso a companhia não pertencesse ao índice; e valor = 1 (um), caso a empresa fizesse parte desse indicador brasileiro. “H3: Empresas pertencentes a carteira do ISE possuem melhor nível de evidenciação das questões ambientais, em relação àquelas não classificadas neste índice".

${ }^{3}$ ISR trata-se de Investimento Sustentável Responsável, também denominado pela sigla em inglês SRI. 
Quadro 4 - Resumo das Hipóteses e Variáveis do estudo

\begin{tabular}{|l|l|l|}
\hline \multicolumn{1}{|c|}{ Hipóteses } & \multicolumn{1}{c|}{ Variáveis utilizadas } & \multicolumn{1}{c|}{ Fonte de dados } \\
\hline 1 - Desempenho da empresa & Vendas Líquidas & Revista Exame \\
\hline 2 - Potencial de Poluição & Grau AAlto e Alto & PNMA $^{4}$ \\
\hline 3 - Índice de Sustentabilidade Empresarial & Pertencer ao ISE & BM\&FBOVESPA \\
\hline
\end{tabular}

Fonte: Elaborado pelo autor (2017).

Ressalta-se que, na operacionalização de algumas hipóteses, considerou-se oportuno converter algumas variáveis em Quartis, de modo a suavizar a distribuição dos dados e permitir melhor comparação entre os diferentes elementos.

De acordo com Marion (2012), Quartil é a medida estatística que divide os coeficientes em 4 partes, sendo que o $1^{\circ}$ Quartil será o valor que deixar $25 \%$ dos elementos do conjunto abaixo de si mesmo e 75\% acima - classificado como RUIM; o 2o Quartil será o valor da mediana dos itens classificado como REGULAR; já o 3ํㅜ Quartil será o valor que apresentar 75\% dos casos abaixo dele e $25 \%$ acima - classificado como BOM; e o $4^{\circ}$ Quartil comporta a totalidade dos elementos, ou seja, $100 \%$ das variáveis investigadas - classificado como ÓTIMO.

\section{ANÁLISE DOS DADOS E DISCUSSÃO DOS RESULTADOS}

Diante das informações citadas na Metodologia, a amostra da pesquisa fora selecionada a partir da acessibilidade dos Relatórios de Sustentabilidade nos dois anos investigados, 2010 e 2015, sendo que as companhias que não apresentaram este documento foram excluídas da seleção. Desta forma, observa-se, portanto, que do total de 100 companhias, apenas 52 divulgaram os relatórios analisados nos dois anos selecionados, sendo habilitadas a compor base de dados do estudo em questão.

Com relação ao setor de atuação, a amostra é bastante heterogênea, na medida em que apresenta empresas de diferentes setores. O Quadro 5 apresenta a classificação setorial da amostra investigada.

Quadro 5 - Composição da amostra por setor

\begin{tabular}{|l|c|c|}
\hline \multicolumn{1}{|c|}{ SETOR } & NÚMERO DE EMPRESAS & Percentual (\%) \\
\hline Energia & 10 & $19,2 \%$ \\
\hline Bens de Consumo & 7 & $13,5 \%$ \\
\hline Autoindústria e Transporte & 6 & $11,6 \%$ \\
\hline Siderurgia, Metalurgia e Mineração & 5 & $9,6 \%$ \\
\hline Varejo & 5 & $9,6 \%$ \\
\hline Química e Petroquímica & 4 & $7,7 \%$ \\
\hline Produção Agropecuária & 3 & $5,8 \%$ \\
\hline Telecomunicações & 3 & $5,8 \%$ \\
\hline Papel e Celulose & 2 & $3,8 \%$ \\
\hline Atacado & 2 & $3,8 \%$ \\
\hline Outros & 5 & $9,6 \%$ \\
\hline TOTAL & $\mathbf{5 2}$ & $\mathbf{1 0 0 , 0} \%$ \\
\hline
\end{tabular}

Fonte: Elaborado pelo autor (2017).

Considerou-se apropriado agrupar, os setores que possuíam apenas 1 companhia, na categoria de "Outros", a saber: Eletroeletrônico; Indústria de Construção; Infraestrutura; Serviços; e Diversos, de modo a facilitar a interpretação dos dados. Desta feita, observa-se, a partir do Quadro 5, que

${ }^{4}$ PNMA - Política Nacional do Meio Ambiente, Lei no 6.938, de 31 de agosto de 1981. 
a concentração maior fora em empresas do setor de Energia, seguido de Bens de Consumo e Autoindústria e Transporte.

\subsection{Análise Preliminar das Hipóteses}

Com o propósito de analisar, previamente, as hipóteses construídas no estudo, foram realizadas Análise de Correspondência (Anacor), Teste Qui-Quadrado e Correlação. É necessário ressaltar que, a validade das inferências feitas, fora efetuada por meio da Análise de Regressão em Painel.

\subsubsection{Nível de Disclosure Versus Desempenho da Empresa}

A primeira hipótese elaborada no estudo fora a existência de correlação positiva entre o desempenho da companhia (sendo definido como proxy o volume de vendas líquidas) e o nível de evidenciação ambiental. Os resultados da Correlação e Regressão encontram-se na Tabela 1.

Tabela 1 - Dados Correlação: Disclosure e Desempenho

\begin{tabular}{cc}
\hline Coeficiente de Pearson & Sig. \\
\hline ,698(a) &, 000 \\
\hline Fonte: Dados da Pesquisa (2017).
\end{tabular}

Os números da Tabela 1 demonstram que há correlação entre as variáveis testadas, e que esta é uma correlação positiva. Além disso, o coeficiente de determinação (R Quadrado) expressa que a variável 'Desempenho' explica o 'Nível de Disclosure' em 48,7\%. De forma geral, a correlação entre as variáveis é Moderada (entre 0,40 e 0,69), no entanto, significativa no nível de $1 \%$.

\subsubsection{Nível de Disclosure Versus Potencial de Poluição}

A segunda hipótese do estudo fora a afirmação que empresas classificadas, na Política Nacional do Meio Ambiente, com atividades de alto impacto ambiental (AAlto e Alto) possuem maior nível de evidenciação ambiental, uma vez que estas atividades possuem grande utilização de recursos naturais, e, por consequência, necessitam demonstrar a preocupação eminente com a Sustentabilidade. A Tabela 2 apresenta os resultados da correspondência.

Tabela 2 - Correspondência entre Disclosure Ambiental e Potencial de Poluição

\begin{tabular}{|c|c|c|c|c|c|}
\hline \multirow{2}{*}{ Potencial de Poluição } & \multicolumn{4}{|c|}{ Nível de Disclosure } & \multirow{2}{*}{ Total - Potencial } \\
\hline & Ruim & Regular & Bom & Ótimo & \\
\hline AAlto & 1 & 0 & 3 & 3 & 7 \\
\hline Alto & 2 & 5 & 0 & 0 & 7 \\
\hline MMédio & 2 & 2 & 2 & 1 & 7 \\
\hline Médio & 5 & 2 & 6 & 7 & 20 \\
\hline Baixo & 3 & 4 & 2 & 2 & 11 \\
\hline Total - Nível & 13 & 13 & 13 & 13 & 52 \\
\hline
\end{tabular}

Como forma de testar a hipótese construída, realizou-se nova classificação, sendo que para as empresas com Potencial de Poluição considerado AAlto e Alto, fora atribuído numeral 1 = Sim, e para as companhias com Potencial de Poluição de nível MMédio, Médio e Baixo, fora atribuído numeral 0 = Não. Desta feita, tem-se novos resultados da correspondência, conforme Tabela 3. 
Tabela 3 - Correspondência entre Disclosure Ambiental e Potencial de Poluição Ajustado

\begin{tabular}{|c|c|c|c|c|c|c|}
\hline \multirow{2}{*}{\multicolumn{2}{|c|}{ Potencial AAlto e Alto }} & \multicolumn{4}{|c|}{ Nível de Disclosure } & \multirow{2}{*}{ Total - Potencial } \\
\hline & & Ruim & Regular & Bom & Ótimo & \\
\hline Não & & 10 & 8 & 10 & 10 & 38 \\
\hline \multirow[t]{2}{*}{ Sim } & & 3 & 5 & 3 & 3 & 14 \\
\hline & Total - Nível & 13 & 13 & 13 & 13 & 52 \\
\hline
\end{tabular}

Analisando as Tabelas 2 e 3, a primeira apresenta uma peculiaridade não visualizável na segunda, uma vez que é possível identificar que as companhias com potencial de poluição considerado AAlto demonstraram nível de evidenciação concentrado em 'Bom' e 'Ótimo', já as companhias com potencial Alto não alcançaram nenhuma destas classificações. Dessa forma, a Tabela 19 explicita que as empresas com atividade de alto impacto ambiental não obtiveram maiores níveis de disclosure, centralizando, a sua maioria, 35,7\%, com classificação 'Regular' de evidenciação.

\subsubsection{Nível de Disclosure Versus Índice de Sustentabilidade Empresarial (ISE)}

A Hipótese 3 procurou associar o percentual de divulgação ambiental com as empresas pertencentes a carteira do ISE, sendo que esse índice tem o propósito de desenvolver um mercado de investimento proporcional com as necessidades da atual sociedade, e incentivar o compromisso moral das organizações, a transparência na divulgação de suas transações e a responsabilidade com o desenvolvimento sustentável. Dessa forma, empresas que fazem parte dessa carteira priorizam uma economia eficiente, controle do meio ambiente e igualdade social, sendo assim, devem possuir maior clareza de suas ações, dessa forma, maior nível de disclosure ambiental. A Tabela 4 demonstra os achados dessa análise.

Tabela 4 - Correspondência entre Disclosure Ambiental e ISE

\begin{tabular}{|c|c|c|c|c|c|c|}
\hline \multirow{2}{*}{ Ano } & \multirow{2}{*}{ Carteira do ISE } & \multicolumn{4}{|c|}{ Nível de Disclosure } & \multirow{2}{*}{ Total - ISE } \\
\hline & & Ruim & Regular & Bom & Ótimo & \\
\hline \multirow{2}{*}{ 옹 } & Não & 9 & 8 & 11 & 9 & 37 \\
\hline & Sim & 4 & 5 & 2 & 4 & 15 \\
\hline \multirow{2}{*}{ 물 } & Não & 9 & 7 & 10 & 8 & 34 \\
\hline & Sim & 4 & 6 & 3 & 5 & 18 \\
\hline
\end{tabular}

Fonte: Dados da Pesquisa (2017).

Com base na Tabela 4, observa-se que os resultados, tanto para o ano de 2010 como para o ano de 2015, se demonstraram similares, e com valores, em cada nível de disclosure, muito próximos, não havendo predominância de companhias pertencentes a carteira do ISE com nível de evidenciação 'Ótimo', nos dois anos. Além disso, o que se verifica é a classificação 'Regular' sendo destaque no período analisado, com 33,3\% das companhias nesse nível, em 2010 e 2015. Para melhor análise da relação fora realizado o Teste Qui-Quadrado, sendo os resultados apresentados na Tabela 5. 
Tabela 5 - Teste Qui-Quadrado: Disclosure Ambiental e Carteira do ISE

\begin{tabular}{|c|c|c|c|c|c|}
\hline Ano & Dimensão & Valor Singular & Inércia & Qui-Quadrado & Sig. \\
\hline \multirow{2}{*}{ 윰 } & 1 & 185 & ,034 & & \\
\hline & TOTAL & & ,034 & 1,780 & ,619(a) \\
\hline \multirow{2}{*}{$\stackrel{10}{\stackrel{2}{2}}$} & 1 & 181 & ,033 & & \\
\hline & TOTAL & & ,033 & 1,699 & ,637(a) \\
\hline
\end{tabular}

Fonte: Dados da Pesquisa (2017).

Verifica-se por meio do Teste Qui-Quadrado que não há significância entre a variável ‘Carteira do ISE' e 'Nível de Disclosure', ou seja, não existe relação entre melhor grau de evidenciação em empresas que pertençam à carteira do ISE.

\subsection{Determinantes do Disclosure Ambiental}

Para a análise dos determinantes do disclosure ambiental, foram testados dois modelos de análise de regressão em painel, o de efeitos fixos e de efeitos aleatórios. Para a determinação de qual modelo é o praticável, fora realizado o Teste de Hausman, em que o resultado apontou um coeficiente Cross-section de Prob. de 0,6491, o qual direciona para a análise de regressão em painel pelo modelo de efeitos aleatórios (Prob. entre 0,10 - 1). Desta feita, a Tabela 6 apresenta os resultados da estimação.

Tabela 6 - Regressão em Painel - Disclosure Ambiental

\begin{tabular}{lcccc}
\hline \multicolumn{1}{c}{ Variável } & Coeficiente & Erro Padrão & Estatística t & Prob. \\
\hline C & 0,039333 & 0,380846 & 0,103278 & 0,9182 \\
DESEMPENHO DA EMPRESA & 0,389194 & 0,112197 & 3,468856 & 0,0012 \\
POTENCIAL DE POLUIÇÃO & 0,053987 & 0,215915 & 0,250037 & 0,8038 \\
CARTEIRA DO ISE & $-0,111700$ & 0,260211 & $-0,429268$ & 0,6699 \\
\hline Unidades Cross-section & 52 & Total de Observações & 104 \\
$\mathrm{R}^{2}$ & 0,732436 & Estat. Durbin-Watson & 1,898662 \\
$\mathrm{R}^{2}$ Ajustado & 0,675100 & Estatística F & 12,77461 \\
& & Prob. (Estatística F) & 0,00000 \\
\hline
\end{tabular}

Fonte: Dados da Pesquisa (2017).

Primeiramente, percebe-se que o modelo é significativo como um todo, ao nível de 0,01 , conforme o teste $\mathrm{F}$. O poder explicativo do modelo, mensurado pelo $\mathrm{R}^{2}$ e $\mathrm{R}^{2}$ Ajustado é de, aproximadamente, $73,24 \%$ e $67,51 \%$ respectivamente, o que mostra bom ajustamento dos dados ao modelo. A hipótese de que os parâmetros estimados são conjuntamente iguais a zero é refutada, como visto na Estatística F. Por fim, a Estatística Durbin-Watson está entre 1,8 e 2,2, o que indica que não há problema de autocorrelação serial dos resíduos.

Observa-se, a partir dos resultados da regressão em painel, que das hipóteses formuladas duas foram rejeitadas/refutadas. As variáveis POTENCIAL DE POLUIÇÃO (H2) e CATEIRA DO ISE (H3) se mostraram não significativas a um nível de $5 \%$, o que se pode inferir que estas variáveis não influenciam o disclosure ambiental.

Por outro lado, a variável DESEMPENHO DA EMPRESA (H1) se confirmou significativa a um nível de $1 \%$, ou seja, possui forte influência sobre o nível de disclosure ambiental praticado pelas companhias investigadas.

Com base nos resultados alcançados, é possível sumarizar e comparar com aqueles que eram esperados, de acordo com a literatura. O Quadro 6 apresenta essa comparação. 


\begin{tabular}{|l|c|c|c|}
\hline \multicolumn{1}{|c}{ Quadro 6- Resumo dos Resultados } \\
\begin{tabular}{|l|c|c|c|}
\hline \multicolumn{1}{|c|}{ Variáveis } & Sinal Esperado & Sinal Observado & Sig. \\
\hline DESEMPENHO DA EMPRESA & $(+)$ & $(+)$ & SIM * \\
\hline POTENCIAL DE POLUIÇÃO & $(+)$ & $(+)$ & NÃO \\
\hline CARTEIRA DO ISE & $(+)$ & $(-)$ & NÃO \\
\hline
\end{tabular}
\end{tabular}

Fonte: Dados da Pesquisa (2017).

* Significativa a um nível de significância de $1 \%$.

A partir do Quadro 6 é possível afirmar que o volume de vendas líquidas é fator que influencia, e possuem relação positiva, na determinação do nível de disclosure ambiental. Em contrapartida, o grau/potencial de poluição da companhia e pertencer a carteira do ISE, são variáveis que não interferem no nível de evidenciação das questões ambientais, pelas companhias investigadas. $\mathrm{O}$ Quadro 7 apresenta um resumo dos testes de hipóteses.

Quadro 7 - Resumo Testes de Hipóteses

\begin{tabular}{|l|l|}
\hline \multicolumn{1}{|c|}{ HIPÓTESE } & \multicolumn{1}{c|}{ RESULTADO } \\
\hline H1 - DESEMPENHO DA EMPRESA & ACEITA/VALIDADA \\
\hline H2 - POTENCIAL DE POLUIÇÃO & REJEITADA/REFUTADA \\
\hline H3 - CARTEIRA DO ISE & REJEITADA/REFUTADA \\
\hline
\end{tabular}

Fonte: Dados da Pesquisa (2017).

Comparando os resultados do estudo com outras pesquisas realizadas, observa-se que: há divergência com o trabalho de Rover (2009) quando o aspecto avaliado é o desempenho da empresa. Confrontando com os resultados obtidos pelo trabalho de Murcia (2009) este apresentou semelhanças com ótica a esta variável. Ademais, também apresentou similaridades com outras pesquisas, corroborando com os estudos de Cunha e Ribeiro (2008); Braga, Oliveira e Salotti (2009); Coelho (2010); Klann e Beuren (2011); e Costa et al. (2013).

Por fim, o trabalho em questão ratifica e reitera-se o defendido pela Teoria da Divulgação, principalmente, com ótica a influência do desempenho econômico da companhia sobre o seu nível de divulgação ambiental, sendo que empresas com maiores volumes de receitas tendem a evidenciar maior número de informações relacionadas ao meu ambiente, fato esse constatado pelo estudo.

\section{CONSIDERAÇÕES FINAIS}

No cenário atual, onde se fala bastante em expansão e lucros, a questão ambiental é sempre lembrada e discutida, visto que a busca incessante por resultados gera intervenções do homem sobre a natureza, ameaçando, assim, a qualidade de vida da sociedade, tanto nessa geração quanto nas próximas. Isto posto, as companhias devem priorizar, em suas divulgações, o accountability, além, é claro, de transparecer, a seus stakeholders, a relação existente entre o seu processo operacional e o meio ambiente, demonstrando, ao mercado, boa governança, compromisso moral com a sociedade e responsabilidade com o desenvolvimento sustentável, aumentando, dessa maneira, a confiabilidade de suas ações.

Destarte, o objetivo precípuo desta pesquisa fora identificar as características endógenas das companhias que explicam o nível de evidenciação das questões ambientais, utilizando-se de estrutura conceitual e métrica aplicada, e defendida, em outros estudos. Ademais, apoiou-se, também, na Teoria da Divulgação, na vertente da categoria da Discricionariedade, a qual defende que a evidenciação de informações pode ser explicada pelas características endógenas das empresas.

O modelo de regressão com dados em painel, que objetivou testar as hipóteses levantadas, apresentou os seguintes resultados gerais: (i) o modelo é significativo como um todo, ao nível de 
1\%; (ii) o poder explicativo da regressão é de, aproximadamente, $67,5 \%$, o que mostra bom ajustamento dos dados ao modelo. (iii) a Estatística $\mathrm{F}$ refuta a hipótese de que os parâmetros estimados são conjuntamente iguais a zero; e (iv) não há problema de autocorrelação serial dos resíduos, comprovado pela Estatística Durbin-Watson.

Com vistas as hipóteses, o modelo estatístico apontou as seguintes conclusões: (i) as variáveis POTENCIAL DE POLUIÇÃO (H2) e CARTEIRA DO ISE (H3), se mostraram não significativas a um nível de $5 \%$, o que se pode inferir que estes fatores não influenciam o disclosure ambiental. Por outro lado, a variável DESEMPENHO DA EMPRESA (H1) se confirmou significativa a um nível de 1\%, ou seja, possuem forte influência sobre o nível de disclosure ambiental praticado pelas companhias investigadas.

Em síntese, é possível afirmar que o volume de vendas das companhias possui influência e relação positiva, na determinação do nível de disclosure ambiental. Em contrapartida, o grau/potencial poluidor da organização e pertencer a carteira do ISE não interferem no nível de evidenciação das questões ambientais, pelas companhias investigadas.

De forma geral, os resultados do estudo apresentam similaridades, e valida, os achados de outras pesquisas como de Rover (2009); Murcia (2009); Braga, Oliveira e Salotti (2009); Coelho (2010); Costa et al. (2013), Los (2014) e Machado (2014), além de ratificar e reiterar-se o defendido pela Teoria da Divulgação.

Para o mercado e a academia, a principal colaboração do estudo está na possibilidade da análise e classificação das empresas brasileiras potencialmente poluidoras, e examinar, além das DFPs, as informações que devem ser priorizadas pela a melhoria dos relatórios socioambientais. Além disso, como se dá a apresentação dos fatores que determinam a divulgação voluntária ambiental, a partir da análise de regressão em painel.

Como limitação do estudo está a não verificação do efeito da variável econômico-financeira rentabilidade, visto que o efeito esperado não se dá no curto prazo. Por exemplo, a variação da rentabilidade de um ano para outro não afetará as decisões das empresas, ou mesmo seus custos políticos. Uma forma alternativa de mensurá-la seria considerar uma perspectiva de médio prazo, que filtre variações aleatórias, decorrentes de outros fatores.

Por fim, como recomendação para futuros estudos poder-se-iam comparar empresas de diversos países, a fim de verificar diferenças e similaridades entre os fatores que explicam o disclosure ambiental no contexto internacional. Do mesmo modo, futuras hipóteses poderiam ser testadas na tentativa de melhorar o poder explicativo do modelo, como participação em índices de sustentabilidade que englobam empresas de mais países, como Dow Jones Sustainability Indexes (DJSI); empresas com práticas de governança corporativa, como as pertencentes aos Níveis 1, 2 e Novo Mercado da Bovespa; entre outros. Outra possibilidade do campo de estudo é agregar, além de variáveis individuais das empresas, fatores culturais e institucionais dos países.

\section{REFERÊNCIAS}

BM\&FBOVESPA. Bolsa de Valores de São Paulo. Listagem - Segmentos de listagem. São Paulo: BM\&FBOVESPA, 2017. Disponível em: <http://www.bmfbovespa.com.br/pt_br/listagem/acoes/segmentos-de-listagem/sobre-segmentos-de-listagem/>. Acesso em: 16 jan. 2017.

Braga, J. P., Oliveira, J. R. S., \& Salotti, B. M. (2009). Determinantes do nível de divulgação ambiental nas demonstrações contábeis de empresas brasileiras. Revista de Contabilidade da UFBA, 3(3), 81-95. Disponível em: <http://www.portalseer.ufba.br/index.php/rcontabilidade/article/view/3819/2790>. Acesso em: 11 out. 2016. 
Calixto, L. (2011). Responsabilidade socioambiental: a divulgação de relatórios na América Latina (Doctoral dissertation).

Coelho, F. Q. (2010). Divulgação de informações voluntárias sobre o meio ambiente: uma análise dos fatores diferenciadores.

da Costa, M. I., Torres, L. S., Gallon, A. V., \& De Luca, M. M. M. (2013). Classificação do conteúdo dos relatórios de sustentabilidade de empresas premiadas por suas práticas de responsabilidade socioambiental. Revista de Educação e Pesquisa em Contabilidade (REPeC), 7(2). Disponível em: <http://www.repec.org.br/index.php/repec/article/view/629>. Acesso em: 10 out. 2016.

da Costa, R. S., \& Marion, J. C. (2007). A uniformidade na evidenciação das informações ambientais. Revista Contabilidade \& Finanças, 18(43), 20-33. Disponível em: <http://www.revistas.usp.br/rcf/article/view/34212/36944>. Acesso em: 20 abr. 2016.

Da Cunha, J. V. A., \& Ribeiro, M. (2008). Divulgação voluntária de informações de natureza social: um estudo nas empresas brasileiras. Revista de Administração-eletrônica, 1(1), 1-23. Disponível em: <http://www.rausp.usp.br/Revista_eletronica/v1n1/artigos/v1n1a6.pdf >. Acesso em: 10 set. 2016.

Damak-Ayadi, S. (2008). Some determinants of social and environmental disclosures in annual reports by French firms. In: Annual Congress of the European Accounting Association (EAA), 31, 2008, Rotterdam. Anais... Rotterdam, 2008.

FIPECAFI. Projeto Exame - Melhores e Maiores. Disponível em: <http://www.fipecafi.org/Consultoria/maiores.html>. Acesso em: 10 mai. 2017.

Freitas, C. D. O., \& Strassburg, U. (2007). Evidenciação das informações ambientais nas demonstrações contábeis de empresas do setor de papel e celulose brasileiras. Campus Cascavel, 4. Disponível em: <http://www.unioeste.br>. Acesso em: 18 abr. 2016.

Gil, A, C. (2009). Como elaborar projetos de pesquisa. 4. ed. São Paulo: Atlas.

de Souza Gonçalves, R., Rodrigues, A. P., Santana, C. M., \& de Oliveira Gonçalves, A. (2013). A influência da origem do controle acionário no nível de social disclosure em empresas brasileiras. Revista de Gestão Social e Ambiental-RGSA, 7(2), 53-70. Disponível em: <https://www.revistargsa.org/rgsa/article/view/577>. Acesso em: 2 out. 2016.

Gray, R., \& Bebbington, J. (2001). Accounting for the Environment. 2. ed. London: Sage.

Gray, R., Kouhy, R., \& Lavers, S. (1995). Constructing a research database of social and environmental reporting by UK companies. Accounting, Auditing \& Accountability Journal, 8(2), 78-101.

Gubiani, C, A., dos Santos, V., Klann, R, C., de Toledo Filho, J, R. (2010). Disclosure dos derivativos nas notas explicativas das empresas dos segmentos de papel e celulose e de carnes e derivados. In: XIII SEMEAD, Anais... . São Paulo: FEA-USP. Disponível em: <http://sistema.semead.com.br/13semead/resultado/trabalhosPDF/470.pdf>. Acesso em: 28 set. 2016.

Jennifer Ho, L. C., \& Taylor, M. E. (2007). An empirical analysis of triple bottom-line reporting and its determinants: evidence from the United States and Japan. Journal of International Financial Management \& Accounting, 18(2), 123-150.

Huppes, L. C. (2014). Os preceitos da sustentabilidade na gestão empresarial: um estudo correlacional sob o viés da percepção de gestores e colaboradores de empresas da região sudoeste do Paraná (Master's thesis, Universidade Tecnológica Federal do Paraná). 
Lima, G. A. S. F. D. (2007). Utilização da teoria da divulgação para avaliação da relação do nível de disclosure com o custo da dívida das empresas brasileiras (Doctoral dissertation, Universidade de São Paulo).

Los, G. Z. (2014). Evidenciação socioambiental: um estudo nas empresas listadas no índice de sustentabilidade empresarial (ISE) da BM\&FBOVESPA.

Machado, D. P. (2014). A evidenciação ambiental como instrumento de gestão da legitimidade social em empresas brasileiras de capital aberto.

Maciel, C. V. (2012). Disclosure ambiental: um panorama evolutivo dos níveis de evidenciação de uma empresa do setor elétrico (Master's thesis, Universidade Federal de Pernambuco).

Marion, J. C. (2012). Análise das Demonstrações Contábeis: contabilidade empresarial. 7a EdiçãoEditora Átlas. São Paulo.

Murcia, F. D. R., \& dos Santos, A. (2009). Fatores determinantes do nível de disclosure voluntário das companhias abertas no Brasil. Revista de Educação e Pesquisa em Contabilidade (RE$\mathrm{PeC}), 3(2), 72-95$.

Nichi, J. (2016). Governança e relatório integrado: discursos e práticas da sustentabilidade corporativa (Doctoral dissertation, Universidade de São Paulo).

Nikolaeva, R., \& Bicho, M. (2011). The role of institutional and reputational factors in the voluntary adoption of corporate social responsibility reporting standards. Journal of the Academy of Marketing Science, 39(1), 136-157.

Nossa, V. (2002). Disclosure ambiental: uma análise do conteúdo dos relatórios ambientais de empresas do setor de papel e celulose em nível internacional (Doctoral dissertation, Universidade de São Paulo).

Paiva, P. R. D., \& Assaf Neto, A. (2001). Evidenciação de gastos ambientais: uma pesquisa exploratória no setor de celulose e papel.

Pedron, A. P. B. (2014). Estudo sobre o impacto da evidenciação de informações ambientais na rentabilidade e valor das empresas listadas na BM\&FBOVESPA.

Pestana, M. H., \& Gageiro, J. N. (2003). Análise de dados para ciências sociais: a complementaridade do SPSS.

Revista Exame. Edição Especial Exame, Melhores e Maiores 2016. As 1000 maiores e melhores empresas do Brasil. ed. 2016, Jul./2016.

Ribeiro, M. D. S. (1992). Custeio das atividades de natureza ambiental (dissertation, Universidade de São Paulo).

Ribeiro, M. D. S. (1998). Custeio das atividades de natureza ambiental (Doctoral, Universidade de São Paulo).

Rosa, F. S. D., Ensslin, S. R., \& Ensslin, L. (2010). Evidenciação ambiental: processo estruturado de revisão de literatura sobre avaliação de desempenho da evidenciação ambiental. Sociedade, Contabilidade e Gestão, 4(2).

da Rosa, F. S., de Sousa Ferreira, A. C., Ensslin, S. R., \& Ensslin, L. (2011). Evidenciação ambiental (EA): contribuição da metodologia multicritério para identificação dos aspectos financeiros para a gestão ambiental. Contabilidade Vista \& Revista, 21(4), 27-61. 
Da Rosa, F. S., Ensslin, S. R., Ensslin, L., \& Lunkes, R. J. (2011). Gestão da evidenciação ambiental: um estudo sobre as potencialidades e oportunidades do tema. Engenharia Sanitária Ambiental, 16(1), 157-166.

Rover, S., Borba, J. A., Murcia, F. D. R., \& Vicente, E. F. R. (2008). Divulgação de informações ambientais nas demonstrações contábeis: um estudo exploratório sobre o disclosure das empresas brasileiras pertecentes a setores de alto impacto ambiental. Revista de Contabilidade e Organizações, 2(3), 53-72.

Rover, S. (2009). Disclosure ambiental de empresas pontencialmente poluidoras: características da informação ambiental e explicações para a divulgação voluntária no Brasil.

Rover, S., Tomazzia, E. C., Murcia, F. D. R., \& Borba, J. A. (2012). Explicações para a divulgação voluntária ambiental no Brasil utilizando a análise de regressão em painel. Revista de Administração, 47(2), 217-230.

Rover, S. (2013). Disclosure socioambiental e custo de capital próprio de companhias abertas no Brasil (Doctoral, Universidade de São Paulo).

Rufino, M. A. Responsabilidade social e ambiental corporativa: determinantes da divulgação de informação voluntária.

SILVA, W. M., de Melo, J. F. M., \& Barbosa, M. D. F. N. (2013). Análise de conteúdo da evidenciação dos investimentos e custos ambientais: um estudo nas empresas do segmento de papel e celulose cadastradas na Bovespa no período de 2009 a 2012. In Anais do Congresso Brasileiro de Custos-ABC.

Sousa, C. B. D. (2013). Valor de mercado e disclosure voluntário: estudo empírico em companhias listadas na BM\&FBOVESPA.

Tannuri, G. (2013). Indicadores de desempenho ambiental evidenciados nos relatórios de sustentabilidade: uma análise à luz de atributos de qualidade.

Verrecchia, R. E. (2001). Essays on disclosure. Journal of accounting and economics, 32(1-3), 97-180. 